\title{
The tidal flushing of multiple-loop animal burrows
}

\author{
S.F. Heron ${ }^{\text {a,b, } * \text {, P.V. Ridd }}{ }^{\text {a }}$ \\ ${ }^{a}$ Marine Geophysical Laboratory, School of Mathematical and Physical Sciences, James Cook University, Townsville Q4811, Australia \\ b Physics Department, Georgetown University, Washington, DC 20057, USA
}

Received 28 May 2007; accepted 22 November 2007

Available online 26 December 2007

\begin{abstract}
Tidal flushing of animal burrows in mangrove swamps provides an effective and important mechanism for transport of salt and other soluble substances. The burrows have complex morphologies consisting of multiple loops. Using established computational modelling techniques, burrow geometries were simulated from characteristic burrow dimensions and the effect of multiple loops on flushing is studied. The computational models show that flushing is enhanced in multiple-loop burrows as upper loops can be completely evacuated, increasing the volume of burrow water removed. The models indicate that there may be a depth limit to which flushing occurs in complex burrow structures. Periscope loops extend further than one characteristic loop depth and are shown to affect the flushing of burrows if the surface-water plume penetrates to their lower depth. Periscope loops with surface openings on the downstream side of the burrow, relative to the tidal inundation, most frequently experience this condition and thus have a great impact on burrow flushing. Field measurements of salinity agree with the hypothesis that there is a depth limit of flushing for complex burrows that is independent of burrow salinity, and suggest a value of $30-35 \mathrm{~cm}$. The measurements also support the suggestion that significant flushing of burrows occurs within a single tidal event. An experiment considered the movement of animals across the interface created by low-salinity surface water and high-salinity burrow water after a partial flushing event. The motion enhances the effective diffusion coefficient of salt by a factor of at least $10^{2}$, as compared with free diffusion of salt in water, resulting in a more even distribution of dissolved salt in the burrow water between tidal inundations. This distribution may lead to an increase in the depth to which flushing occurs during subsequent inundations.
\end{abstract}

(C) 2007 Elsevier Ltd. All rights reserved.

Keywords: burrows; computer simulation; flushing time

\section{Introduction}

Animal burrows are excavated in the sediment in and around lakes, rivers, estuaries and ocean coasts. The inundation of these burrows by increased water levels (e.g., tides) can cause flushing of the burrows. This exchange of surface and burrow waters also involves the transport of any dissolved materials, including salt, nutrients, oxygen and toxins. The exchange of salt is of particular importance to the survival of estuarine mangrove swamps. Evaporation at the swamp surface precipitates salt that can be reabsorbed by the remaining

\footnotetext{
* Corresponding author. Marine Geophysical Laboratory, School of Mathematical and Physical Sciences, James Cook University, Townsville Q4811, Australia.

E-mail address: scott.heron@noaa.gov (S.F. Heron).
}

groundwater, thus increasing the salt concentration. In addition to this, as the mangrove roots absorb groundwater they exclude salt, thereby increasing the salt concentration around the roots. Some mangrove species are able to exclude almost all dissolved salt from groundwater, while others exclude $80-90 \%$ of salt at the root and excrete the remainder at the leaves (Scholander et al., 1968; Ball, 1988). Lugo et al. (1975) measured the transpiration rate within mangrove swamps to cause a water loss at the canopy leaves of approximately $1 \mathrm{~mm}$ per day. The transpiration and evaporation processes are often considered together as evapotranspiration. Wolanski and Ridd (1986) estimate the evapotranspiration rate in mangrove swamps to be $2 \mathrm{~mm} \mathrm{day}^{-1}$. The increase in sediment salt concentration caused by evapotranspiration can cause the stunting, and ultimately the death, of the mangal (Soto and Jimenez, 1982; Semeniuk, 1983; Tomlinson, 
1986). In essence, the transpiration process can contribute to the demise of mangroves unless the salt can be removed.

Diffusion of salt away from the mangrove root is greatly impeded by the impermeability of the sediment. Hollins et al. (1999) calculated the diffusion coefficient for salt in mangrove sediment to be $D=4.6 \times 10^{-5} \mathrm{~m}^{2}$ day ${ }^{-1}$, approximately one-third of the value for salt in water (Weast, 1981). Passioura et al. (1992) considered the mangrove sediment as a vertical plane and approximated the diffusion time over a distance, $l$, by $l^{2} / D$. This suggests that diffusion of salt from a depth of $0.5 \mathrm{~m}$ would take 15 years - a rate of salt removal that would not sustain survival of the mangroves. Thus, another mechanism of salt removal is necessary to prevent salinisation of the soil.

Diffusion of salt into nearby animal burrows, and the subsequent flushing of these burrows, provides a mechanism by which salt can be quickly removed from around roots.

Flow through sediment macropores has led to greater understanding of solute exchange between surface water and groundwater (Allanson et al., 1992; Webster, 1992; Harvey et al., 1995; Ridd, 1996). Stieglitz et al. (2000) and Hollins (2001) showed that significant flushing of burrows occurs whenever the burrow openings are inundated by tidal water. Stieglitz et al. (2000) replaced the burrow water with a sugar solution of the same density, and measured the conductivity change as tide water flushed the solution. From this, they propose that complete flushing can occur within the span of a single tidal event. Hollins (2001) monitored burrow flushing during a tidal inundation using two methods. The first method extracted burrow water samples throughout the inundation and measured the oxygen concentration. Oxygen-rich, tidal water was measured as it entered the burrow, thus monitoring tidal flushing. The second method involved mixing a rhodamine dye tracer into the burrow water and extracting samples during the tidal period for testing. Measurements of relative fluorescence indicated the proportion of dye that had remained in the burrow. The two methods were consistent in the observation that approximately one-third of the burrow water is flushed, i.e., that complete flushing of the burrow does not usually occur during a single tidal event.

Heron and Ridd (2001) developed a computational fluid dynamics model by which the flushing of burrows could be predicted. The slope of the incoming tidal water provides a pressure gradient across the burrow, inducing flow through the burrow. Surface obstructions to the flow (e.g., roots) and their effect on flushing rates were investigated, as were geometries of various complexities. It was suggested that significant flushing of burrows can occur during a single tidal event. Heron and Ridd (2003) continued this work by incorporating the effects of density variation for simple burrow geometries. Salt diffusion from the sediment into the burrows increases the density of the burrow water, as compared with the inundating surface water. Heron and Ridd (2003) compared analytical predictions and experimental data with computational models for the flow. The increased burrow water density hindered the rate of flushing of burrows and, under some combinations of surface-water slope and density, would permit only partial flushing of the burrows. The computational models showed good agreement with experiment and theory. A prediction was developed for the depth to which surface water would enter a burrow,

$d_{1}=k \frac{\rho_{1} S_{0} L}{\Delta \rho}+d_{\mathrm{turb}}$

where $k=1.1$ is an empirical scaling parameter, $\rho_{1}$ is the surface-water density, $S_{0}$ is the surface-water slope, $L$ is the distance across burrow openings, $\Delta \rho$ is the difference between surface and burrow densities, and $d_{\text {turb }}$ is an additional constant due to turbulence at the burrow openings. Heron and Ridd (2003) suggest that the final term is related to the diameter of the burrow. Note that, from Eq. (1), the surface-water penetration depth does not depend upon the depth of the surface water.

The consistency of the models by Heron and Ridd (2003) with their experimental work permits the use of the computational methods to examine flushing in more complex burrow structures. Animal burrows have been observed to reach depths of $1.2 \mathrm{~m}$ (Stieglitz et al., 2000) and to consist of multiple loops. The work reported here furthers that of Heron and Ridd (2003) to investigate the flushing of complex burrow structures with variable density surface and burrow waters.

Observations of casts of burrows suggest that there is a characteristic distance between horizontal burrow sections. This characteristic depth is illustrated schematically in Fig. 1. The majority of vertical burrow sections extend between adjacent horizontal sections. However, some reach further than the characteristic depth, linking non-adjacent horizontal burrow sections to each other, or to the surface. Such longer vertical sections are referred as "periscope" loops, and are shown in

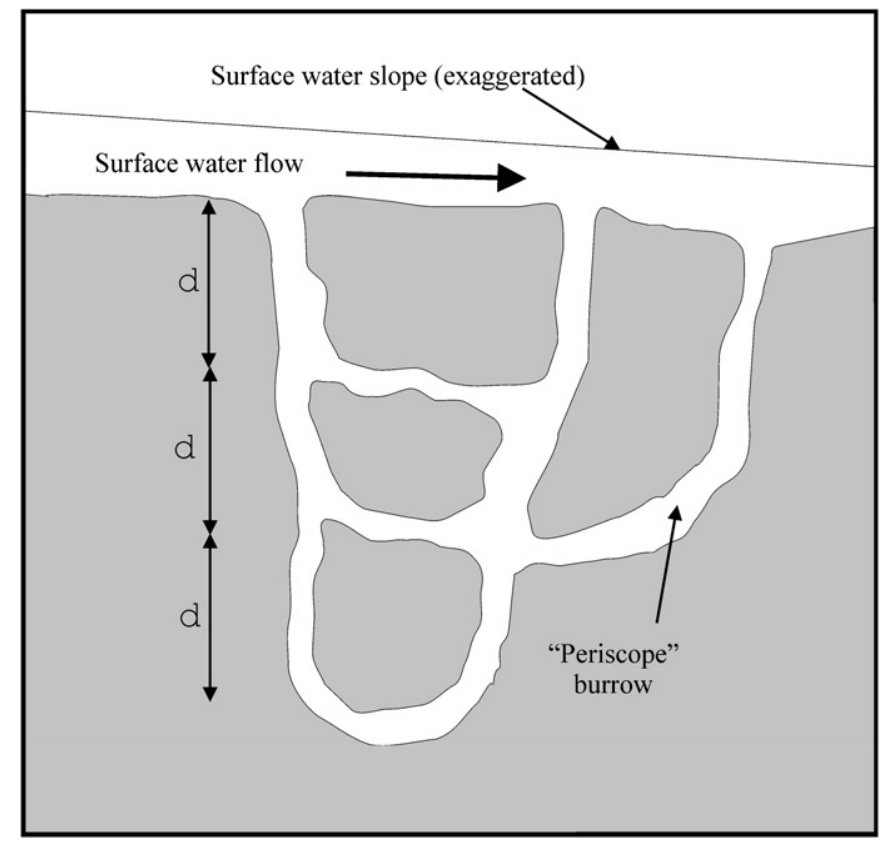

Fig. 1. Schematic illustration of an animal burrow in a mangrove swamp showing multiple-loop and periscope structures. Burrow loops have a characteristic depth, $d$, while periscope loops extend over greater depths. 
Fig. 1. Computational studies examining the effects of multiple loops and periscope loops are presented here.

Field measurements of burrow salinity are undertaken for comparison with the models. Water samples are extracted from several depths within burrows to monitor infiltration of tidal water.

If burrows are only partially flushed during a single tidal event, as supported by Heron and Ridd (2003), mixing can occur between the introduced surface water and the higher-salinity burrow water that has remained. Motion of resident animals through the salinity interface may enhance any diffusive mixing of the burrow and surface waters. This would reduce burrow water salinity at depth and, by Eq. (1), increase the theoretical depth to which flushing occurs. An experiment was developed to investigate the effect of the motion of the burrow residents on the distribution of salt through the burrows.

\section{Methods}

\subsection{Computational modelling}

The modelling of burrow flushing was performed in twodimensions using the Fluid Dynamics Analysis Package, FIDAP. This package uses the finite-element method to solve the isothermal Navier-Stokes equations (Fluid Dynamics International, 1993):

Continuity : $\frac{\partial \rho}{\partial t}+\nabla \cdot \rho \boldsymbol{u}=0$,

Momentum : $\quad \rho\left(\frac{\partial \boldsymbol{u}}{\partial t}+\boldsymbol{u} \cdot \nabla \boldsymbol{u}\right)=-\nabla p+\nabla \cdot \boldsymbol{\tau}-\rho \boldsymbol{g}+\rho \boldsymbol{f}$,

$$
\begin{aligned}
\text { Transient }+ \text { Convective }= & \text { Pressure }+ \text { Viscous } \\
& - \text { Buoyancy } \\
& + \text { Body force }
\end{aligned}
$$

where the symbolism is as follows: $\rho$ - density; $\boldsymbol{u}$ - velocity; $\nabla-$ gradient, divergence operator; $p-$ pressure; $\boldsymbol{\tau}-$ stress tensor; $\boldsymbol{g}$ - gravity; $t$ - time; $\boldsymbol{f}$ - body force.

FIDAP automatically selects the time-step for the numerical calculation to optimise the advancement of the model while maintaining convergence. The time-step is determined for each iteration of the model and generally increases throughout the simulation as the flow, and thus the calculations, becomes more stable.

The incoming tidal slope provides the boundary condition for the surface-water flow; i.e., no velocity values are explicitly defined. Applying a pressure difference, equivalent to the slope, across the model domain has been successful in simulating the vertical velocity profile. More details of the model can be found in Heron and Ridd (2001).

Salt concentration, and its influence upon the flow, was modelled by considering salt as a negatively buoyant tracer. As the density difference between surface and burrow waters is small compared with their magnitude, the Boussinesq approximation was appropriate. This assumes that density is constant throughout the momentum equation except in the Buoyancy term of Eq. (2). In this term the buoyancy depends upon the tracer concentration, $c$. Conservation of the salt tracer required the following equation to be solved concurrently with the continuity and momentum equations:

$$
\begin{aligned}
\text { Tracer : } \rho\left(\frac{\partial c}{\partial t}+\boldsymbol{u} \cdot \nabla c\right)=\rho \nabla \cdot( & \alpha \nabla c)+q_{c}+R \\
\text { Transient }+ \text { Convective }= & \text { Diffusive } \\
& + \text { Source }+ \text { Reaction }
\end{aligned}
$$

where $\alpha$ is the molecular diffusivity.

The molecular diffusivity of burrow salt was selected as that defined by Nye and Tinker (1977) in water at $25^{\circ} \mathrm{C}$, $\alpha=1.6 \times 10^{-9} \mathrm{~m}^{2} \mathrm{~s}^{-1}$. Burrow flow remains laminar for speeds up to at least $2 \mathrm{~cm} \mathrm{~s}^{-1}$. Thus, turbulent diffusion should be small for speeds around this value. Heron and Ridd (2003) discuss further the details involved with modelling varying densities.

The continuity and momentum equations were initially solved for time independent (steady-state) profiles of velocity and pressure, assuming constant density throughout the model domain. These solutions provided initial conditions for the transient, density-dependent models.

A resin cast of a Sesarma messa burrow was made by Stieglitz et al. (2000) and is shown in Fig. 2. This cast shows structural characteristics that are typical of burrows observed in healthy Rhizophora spp. forests in North Queensland, Australia. The morphological structure of the burrow shows several burrow loops through the $1.2 \mathrm{~m}$ depth. Bifurcations in the burrow occurred at characteristic depths of $20-30 \mathrm{~cm}$. In addition to these loops, 'periscope' loops were observed to connect burrow levels over depths of $40-50 \mathrm{~cm}$, effectively bypassing one characteristic loop depth. Stieglitz et al. (2000) reported that burrow sections ranged in diameter from 4 to $11 \mathrm{~cm}$.

While burrow structures would require three-dimensional modelling to fully describe them, two-dimensional modelling does provide valid information regarding the flushing characteristics of complex burrows, as shown by Heron and Ridd (2001, 2003). Modelling of a specific burrow structure would not necessarily provide typical information about flow in all burrows. By employing characteristic dimensions to describe the burrows, the solutions for the burrow flow are no more or less correct than those found for any specific geometry when generalised to describe flushing patterns in burrows.

The characteristic burrow dimensions selected were: burrow width, $7 \mathrm{~cm}$; loop depth, $27 \mathrm{~cm}$; surface opening separation, $47 \mathrm{~cm}$. An obstruction to the surface-water flow (mangrove root) was included between the surface openings, following the analysis of Heron and Ridd (2001), to increase the pressure difference across the burrow openings. Such roots are common around burrow openings and the dimension of the root was chosen to be $4 \mathrm{~cm}$ based on observations during the field study (described in the next section). The burrow design mimicked the structure of observed burrows and, in two-dimensions, somewhat resembles a ladder (Fig. 4). While the geometry is 


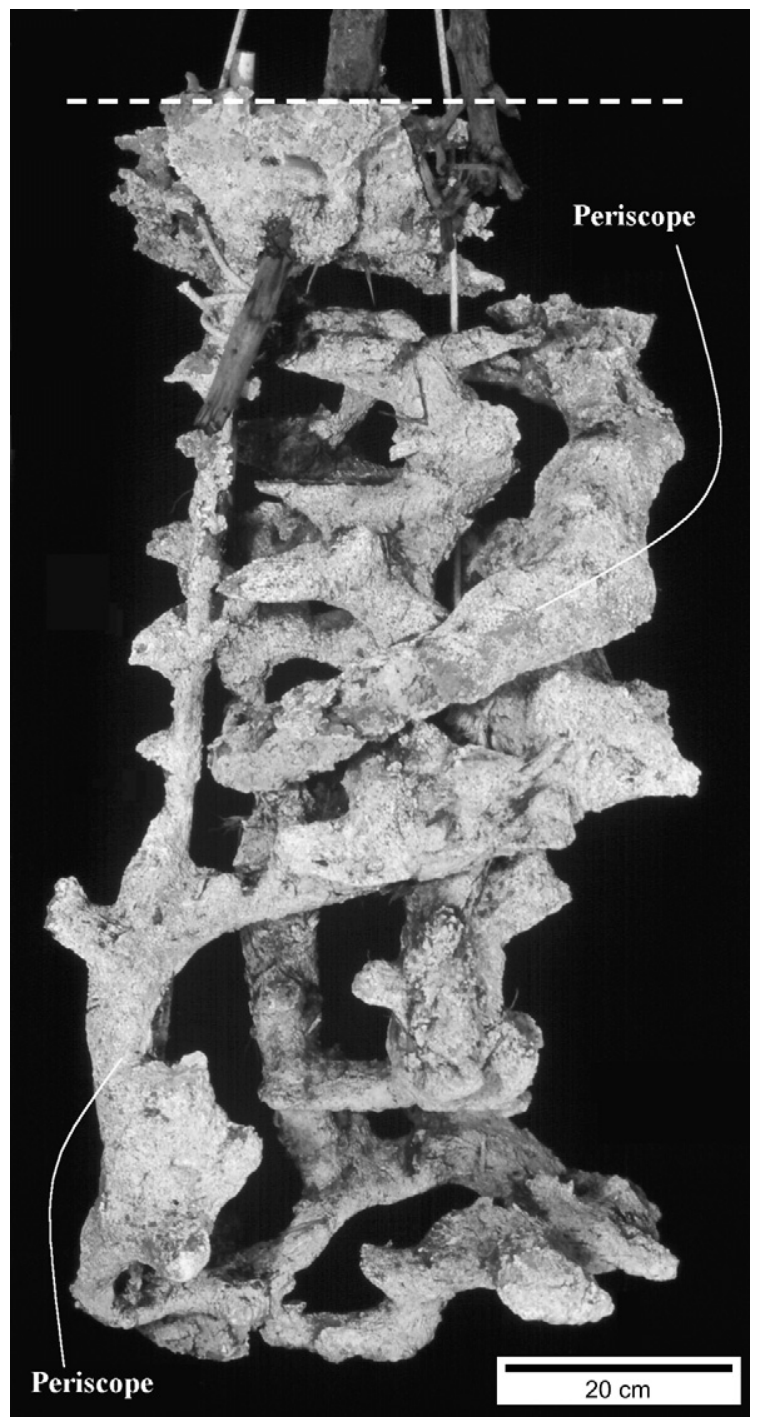

Fig. 2. Photograph of resin cast of a Sesarma messa burrow. The level of the swamp surface is marked with a dashed line (courtesy of T. Stieglitz).

simplified, it characterises the structure of observed burrows. Pressure and buoyancy conditions equivalent to surface-water slopes of $(4,8) \times 10^{-4}$ and density differences between surface and burrow waters of $(0.25,0.5,1) \mathrm{g} \mathrm{l}^{-1}$ were modelled. Burrow geometries involving periscope loops were investigated using the same ranges of surface slope and density differences.

\subsection{Field measurements of salinity}

The field study was conducted in a mangrove swamp adjacent to Gordon Creek in Townsville, Queensland, Australia. Three burrows (labelled A, B and C) were located using a conductivity probe, following the procedure described in Heron et al. (2002). The forest around the burrows was dominated by Rhizophora stylosa of approximate height $8 \mathrm{~m}$, interspersed with Avicennia marina. The proximity of the burrows (within $8 \mathrm{~m}$ of each other) suggested that they would be of similar depths and would experience similar environmental conditions. For each burrow structure, burrow loops at three depths were located from which water samples could be extracted. The depths of these loops are described in Table 1. To confirm that the three loops were part of the same burrow, water was evacuated from the deepest loop, thus draining the upper loops. The volumes of the burrows were estimated to each be approximately 501 .

Medical-grade tygon tubing was inserted into the burrows to each depth and a pipette used to extract samples. Water was first drawn from the burrow loop to rinse any impurities from the tubing walls and then discarded. The water sample for measurement was then drawn into the pipette and filtered through a $0.45 \mu \mathrm{m}$ non-pyrogenic particle filter to remove any suspended sediment. In each case the burrow water was sampled in order of shallowest to deepest loop. Salinity measurements were made using a refractometer, the error of which was determined as 1 practical salinity unit (psu). Samples were extracted approximately every second day during the period 30 Oct-22 Nov 2000 for burrow A, and for the period 0922 Nov 2000 for burrows B and C. The time of sampling was around $3 \mathrm{pm}$, after a tidal inundation (if applicable). Recorded rainfall and the number of inundating tides since the previous measurement are shown in Table 2 for the duration of the study. The swamp elevation was approximately $2.9 \mathrm{~m}$ Australian Height Datum (AHD), so high tides greater than this value would inundate the burrows. The rainfall values, obtained from the Bureau of Meteorology, were recorded at the Townsville airport ( $6 \mathrm{~km}$ from the site). The rainfall data listed in Table 2 are the cumulative total since the previous listed measurement, to 09:00 h on the day of record. Rainfall of less than $0.1 \mathrm{~mm}$ is referred to as "Trace".

\subsection{Enhanced salt diffusion by animal motion}

An experiment was devised to determine the effect on burrow water mixing due to the motion of inhabiting animals. After a tidal event that partially flushes a burrow, less-dense "surface" water exists in the upper regions of the burrow above the higher-density burrow water, deeper in the burrow (Heron and Ridd, 2003). Mixing of these waters across the density interface will reduce the burrow water density deep in the burrow, which can lead to a greater flushing depth on the subsequent tidal inundation. One mechanism by which mixing can take place is by the movement of animals within the burrow.

To simulate the animal motion, a vertical tube was partfilled with a salt solution of concentration $C$, coloured with food dye to act as a tracer. Fresh water was slowly run into the remainder of the tube so as to maintain a distinct interface between the two solutions. A plastic model crab, attached to

Table 1

Sampling depths for the three burrows for salinity analysis

\begin{tabular}{llll}
\hline Burrow & \multicolumn{2}{l}{ Burrow depth $(\mathrm{cm})$} & \\
\cline { 2 - 4 } & Top & Middle & Bottom \\
\hline A & 5 & 39 & 50 \\
B & 5 & 23 & 57 \\
C & 5 & 27 & 57 \\
\hline
\end{tabular}


Table 2

Environment conditions at measurement site, 30 Oct-22 Nov 2000

\begin{tabular}{llcl}
\hline Date (2000) & $\begin{array}{l}\text { Burrow/s } \\
\text { sampled }\end{array}$ & $\begin{array}{l}\text { Rainfall } \\
(\mathrm{mm})\end{array}$ & $\begin{array}{l}\text { Number of } \\
\text { inundating } \\
\text { tides }\end{array}$ \\
\hline $30 \mathrm{Oct}$ & $\mathrm{A}$ & 22.4 & 0 \\
$01 \mathrm{Nov}$ & $\mathrm{A}$ & 0 & 0 \\
$03 \mathrm{Nov}$ & $\mathrm{A}$ & Trace & 0 \\
$05 \mathrm{Nov}$ & $\mathrm{A}$ & Trace & 0 \\
$07 \mathrm{Nov}$ & $\mathrm{A}$ & 41.0 & 1 \\
$09 \mathrm{Nov}$ & $\mathrm{A}, \mathrm{B}, \mathrm{C}$ & 1.4 & 3 \\
$11 \mathrm{Nov}$ & $\mathrm{A}, \mathrm{B}, \mathrm{C}$ & 89.2 & 4 \\
$13 \mathrm{Nov}$ & $\mathrm{A}, \mathrm{B}, \mathrm{C}$ & 9.6 & 3 \\
$15 \mathrm{Nov}$ & $\mathrm{A}, \mathrm{B}, \mathrm{C}$ & 31.4 & 2 \\
$17 \mathrm{Nov}$ & $\mathrm{A}, \mathrm{B}, \mathrm{C}$ & 42.8 & 1 \\
$18 \mathrm{Nov}$ & $\mathrm{A}, \mathrm{B}, \mathrm{C}$ & 0.2 & 1 \\
$20 \mathrm{Nov}$ & $\mathrm{A}, \mathrm{B}, \mathrm{C}$ & 1.2 & 1 \\
$22 \mathrm{Nov}$ & $\mathrm{A}, \mathrm{B}, \mathrm{C}$ & 3.2 & 3 \\
\hline
\end{tabular}

a piece of fishing line, was raised through the interface and farther up the tube, as shown in Fig. 3. After allowing the mixture to settle, the extent to which the dyed water penetrated the clear water from the position of the initial interface, $\Delta z$, was measured. The penetration distance of dyed water was selected due to the ease of observation, compared with that of the clear water into the dyed water. It is reasonably assumed that the penetration distances will be equal, and therefore that the mixed layer depth will be double the measured value. After settling the crab was allowed to pass down across the interface region and the mixed depth was again measured. The procedure was repeated for several interface crossings.

The vertical tube selected had an internal diameter of $3 \mathrm{~cm}$ and was half-filled with a $3 \mathrm{gl}^{-1}$ salt solution. The remainder of the tube was filled with clear fresh water. The average terminal speed of the crab falling under gravity through the liquid was approximately $6.5 \mathrm{~cm} \mathrm{~s}^{-1}$. For consistency, the crab was pulled up through the interface at the same speed; no observations were made of actual crab motion. The time between interface traversals was greater than the time for turbulent motion to dissipate $(10-15 \mathrm{~s})$.

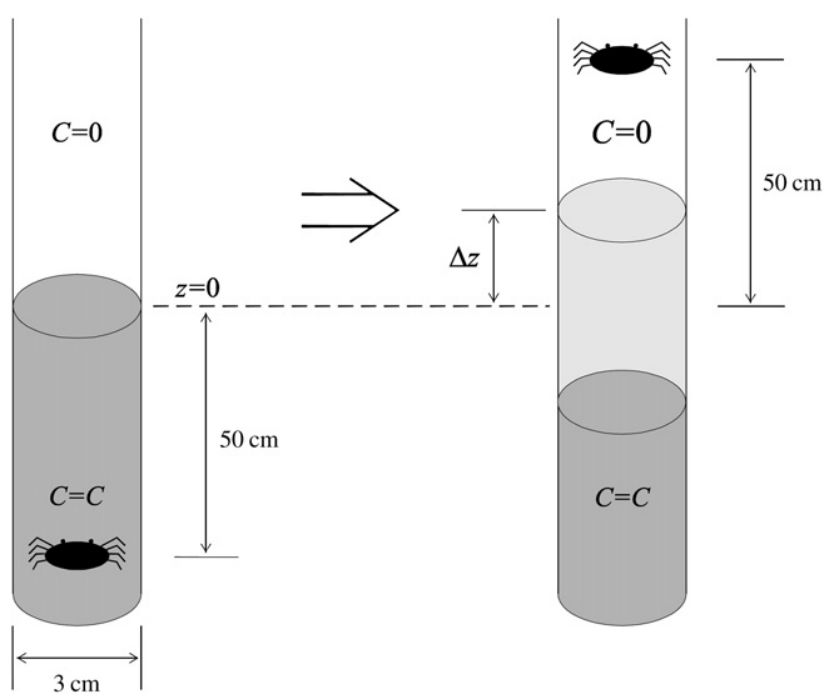

Fig. 3. Apparatus for measuring enhanced mixing due to animal motion.

\section{Results}

\subsection{Computational modelling}

The model grid used nine nodes evenly spaced in quadrilateral finite elements across the width of the burrows. This grid was selected to satisfy the numerical turbulence conditions for minimum cell-size (include the viscous and transitional sublayers) while maintaining computational efficiency. The overall success of a model depends upon independence of the solution from the numerical grid. This was investigated by comparing the numerical solution of a particular grid with the solution determined using a finer resolution grid. Close similarity between the solutions suggests that numerical errors are sufficiently small. These comparisons showed that any spatial errors in the models were indeed sufficiently small to provide confidence in the model results.

Surface flow velocities for the models (with a surface root) ranged from 13 to $19 \mathrm{~cm} \mathrm{~s}^{-1}$ for surface-water slopes of (4, $8) \times 10^{-4}$. These compare favourably with observed flow rates $\left(10-20 \mathrm{~cm} \mathrm{~s}^{-1}\right)$ and surface-water slopes $\left(1.6-6.6 \times 10^{-4}\right)$ during tidal inundations (Heron and Ridd, 2001). Modelled burrow velocities rarely exceeded $1 \mathrm{~cm} \mathrm{~s}^{-1}$, indicating that the burrow flow remained laminar.

The computational models of the ladder geometry (Fig. 4) showed that if surface water could penetrate to the depth of a horizontal loop section, then that section would be flushed out. Fig. 4a shows this effect for surface slope and density difference of $4 \times 10^{-4}$ and $1 \mathrm{~g} \mathrm{l}^{-1}$, respectively. Less-dense (less saline) surface water (blue) enters the burrow, displacing burrow water (red). As flushing progresses, the density anomaly as compared with the surface water is indicated by the spectrum. After clearing the first horizontal loop, the downstream opening is flushed due to the positive buoyancy of the lessdense surface water (Fig. 4b). As the ratio of surface slope to density difference was increased, the models indicated that the depth to which flushing would occur, and thus the percentage of the burrow water flushed, approached an upper limit of about $70 \mathrm{~cm}$ ( $\sim 70 \%$ of burrow volume).

Periscope loops were added to the ladder geometry between horizontal sections, or from the surface to a subsurface horizontal section. Fig. 5 shows a burrow geometry with a periscope loop that provides an additional downstream surface opening. The greater distance across the surface openings corresponds with an increased pressure difference, that, by Eq. (1), should increase the depth to which flushing occurs. Fig. 5a illustrates the model results for slope and density parameters of $4 \times 10^{-4}$ and $1 \mathrm{gl}^{-1}$, respectively, and shows that the initial flushing is consistent with the results of the ladder geometry. After the first horizontal section is flushed (Fig. 5b), the surface-water plume rises to clear the loop, and surface water is also pushed deeper due to the pressure difference between the upstream and periscope openings. As time continues, the surface-water plume reaches the deep end of the periscope (Fig. 5c) and, due to positive buoyancy, flushes the periscope. Hydrostatic equilibrium is reached with the lower section of burrow remaining unflushed (Fig. 5d). 


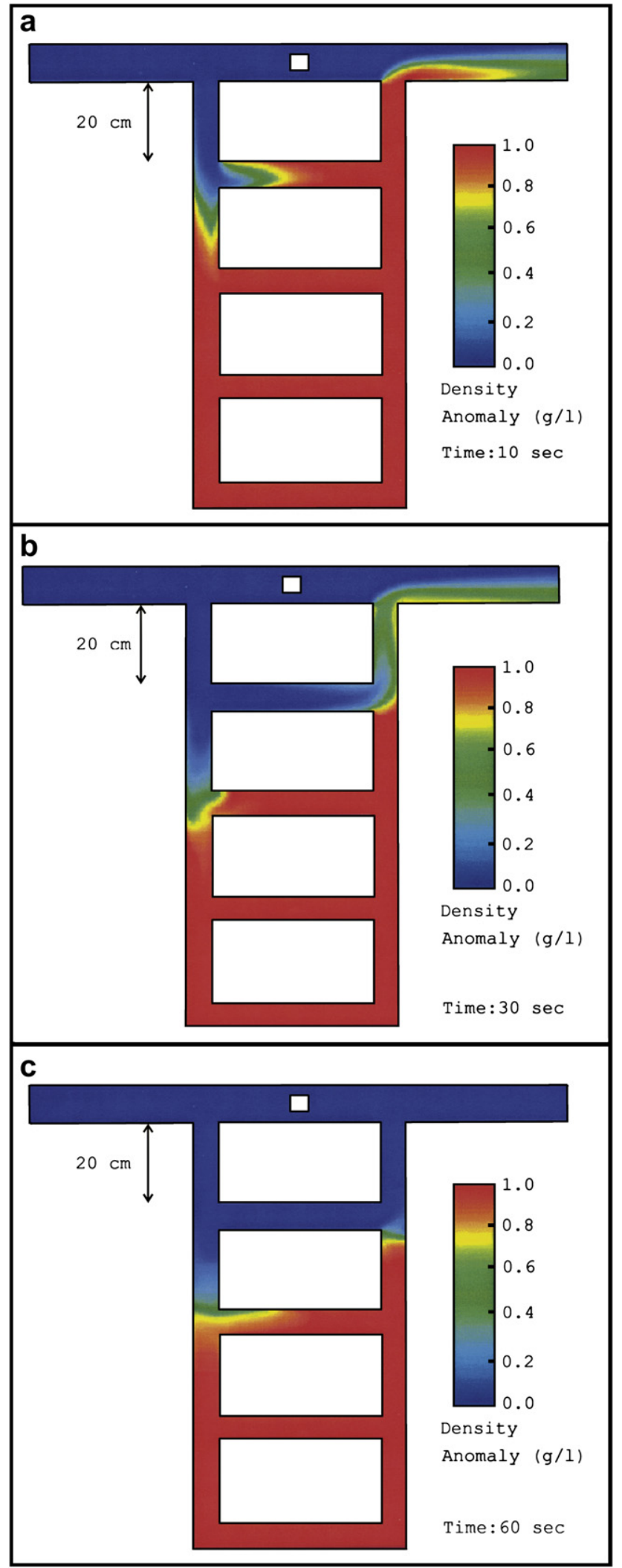

Further models with one or more periscope loops augmented to the ladder geometry in various locations suggest that periscope burrows significantly enhance flushing only when the surface-water plume reaches to the lowest depth of the periscope section. The greatest volume of burrow water flushed occurred when a periscope loop was located on the downstream side of the burrow and with a surface opening (as in Fig. 5). Under surface slope and density-difference conditions where the surface plume did not reach to the lower depth of the periscope loop, the models indicated that periscope loops neither assisted nor hindered flushing. However, if the conditions of surface slope, density difference and periscope depth are such that the surface-water plume does reach to the lower depth of a periscope loop, then periscopes at depth provide an efficient flushing mechanism.

\subsection{Field measurements of salinity}

The salinity time series for each of the burrows through the study period are shown in Fig. 6. Plot (a) shows the daily rainfall as ' $x$ ' and the higher high tide as ' + '. The swamp elevation ( $2.9 \mathrm{~m} \mathrm{AHD}$ ) is indicated by the dashed line to show when the burrows were inundated. The first inundation occurred on 06 Nov 2000 and the burrows were inundated at least once on each subsequent day. Plots (b), (c) and (d) show the salinities at the three depth levels for burrows A, B and C, respectively (see Table 2 for depths).

No samples could be extracted from the top pipe of burrow A on 01 and 03 Nov 2000 as the groundwater level had fallen below this depth. Samples were not taken on 05 Nov 2000 as the pipette broke.

The salinity of the surface water was measured during tidal events on three days towards the end of the study period (18, 20, and 22 November 2000). The salinities, measured using the refractometer, are shown in Table 3.

\subsection{Enhanced salt diffusion by animal motion}

The extent to which the dye reached into the fresh water, $\Delta z$, was measured from the initial interface position. Fig. 7 displays the mean $\Delta z$ value for each traversal, averaged over repeat experiments. A straight line through the origin was fitted to the data, and has a slope of $4.5 \mathrm{~cm} /$ traversal. This suggests that each traversal of the crab mixed the interface $4.5 \mathrm{~cm}$ above and below, i.e., a total mixing distance of $9 \mathrm{~cm}$.

Fig. 4. Density anomaly from surface-water density for "ladder" geometry burrow from computational model. Less-saline surface water is blue, burrow water is red; the spectrum between these reflects the distribution between the minimum and maximum salinities (density). Surface flow across the domain is from left to right. Parameters are surface slope $=4 \times 10^{-4}$ and density difference between surface and burrow waters $=1 \mathrm{gl}^{-1}$. (a) Surface-water plume reaches the depth of the first burrow loop $(t=10 \mathrm{~s})$. (b) Surface water has cleared the horizontal loop and thus flushes burrow water from the upper loop $(t=30 \mathrm{~s})$. (c) Hydrostatic equilibrium is attained before the second horizontal section can be flushed $(t=60 \mathrm{~s})$. 


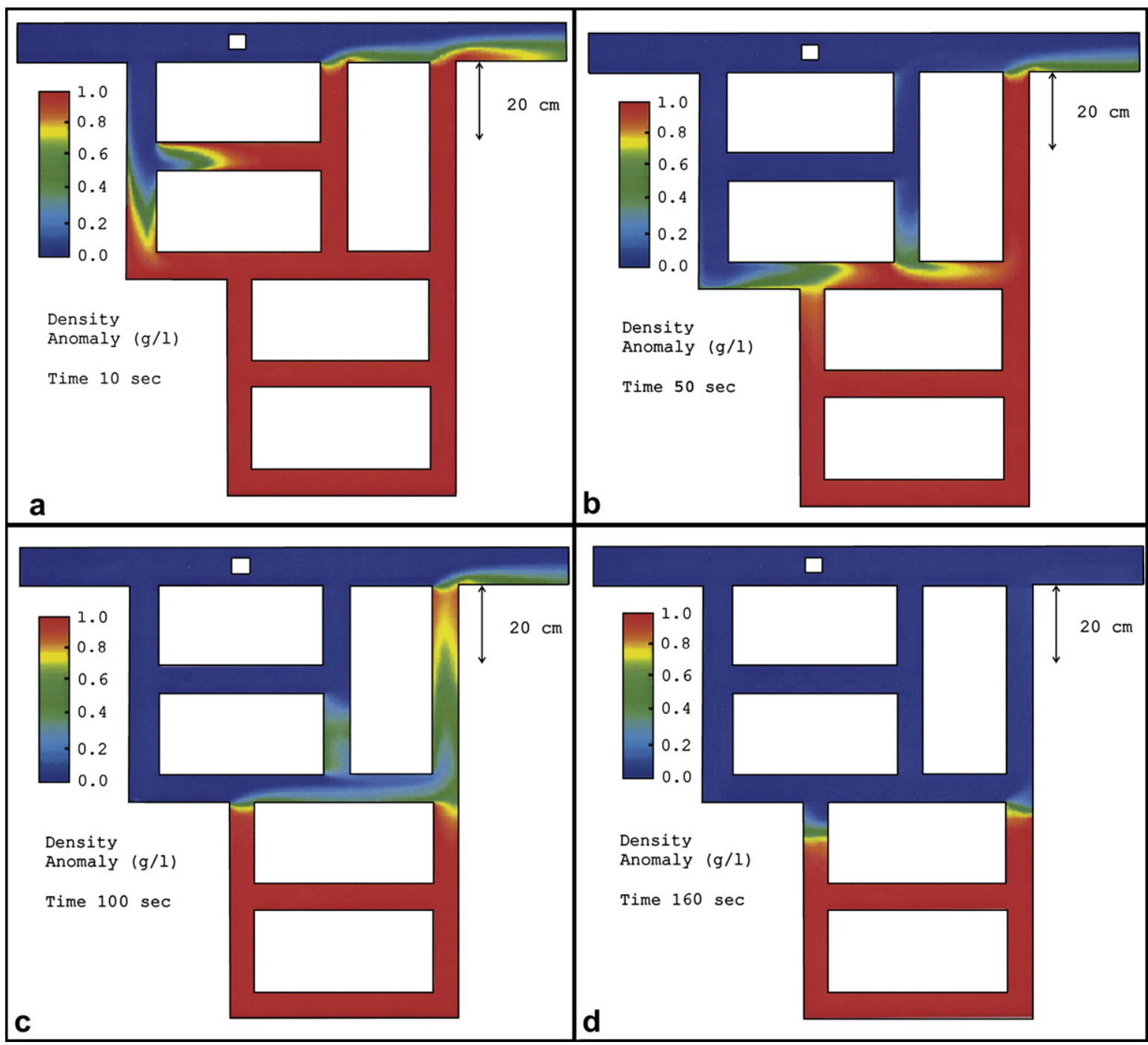

Fig. 5. Density anomaly from surface-water density for "periscope" geometry burrow from computational model. Less-saline surface water is blue, burrow water is red; the spectrum between these reflects the distribution between the minimum and maximum salinities (density). Surface flow across the domain is from left to right. Parameters are surface slope $=4 \times 10^{-4}$ and density difference between surface and burrow waters $=1 \mathrm{~g}^{-1}$. (a) Surface-water plume reaches the depth of the first burrow loop. Burrow water is evacuated at both downstream openings $(t=10 \mathrm{~s})$. (b) Surface water has cleared the horizontal loop and flushed the upper loop. At the upstream opening, the surface-water plume has reached the second loop; at the middle opening, the surface-water plume is moving downwards $(t=50 \mathrm{~s})$. (c) Surface water has filled the second horizontal loop and is flushing burrow water out the periscope opening $(t=100 \mathrm{~s})$. (d) Hydrostatic equilibrium is attained after the periscope is flushed $(t=160 \mathrm{~s})$.

\section{Discussion}

The computational models suggest that when the pressure difference across the surface burrow openings is sufficient to penetrate to the depth of the upper loop/s of multiple-loop burrows, the percentage of burrow water flushed is increased, as compared with a single-looped burrow. In addition, the upstream surface plume can then push deeper into the burrow, flushing more burrow water and possibly more loops, until hydrodynamic equilibrium between the surface pressure difference and density difference of the surface and burrow waters is reached (Fig. 4c). The model output indicates a significant flushing of burrows during a single tidal event, consistent with the observations of Stieglitz et al. (2000) and Hollins (2001). Modelled periscope loop geometries suggest that such loops can further enhance the flushed volume.
Heron and Ridd (2003) noted that density-variable computational models for single-loop burrows over-predicted the theoretical prediction of surface plume depth by $33 \%$, and the experimental results by $21 \%$. This was attributed to differences in the turbulent roughness parameters of the models compared with theory and experiment. The discrepancy from the FIDAP-generated roughness was less significant than the slope-induced pressure difference, the primary cause for flushing. The same definition of roughness (generated by FIDAP) has been used in these models and so the predicted depth to which flushing occurs may be over-predicted by the models. This, in turn, could also influence the volume flushed and the time taken to do so.

However, the process by which multiple-loop burrows are flushed and the prediction that a significant proportion of the burrow is flushed are credible. By flushing one or more burrow 


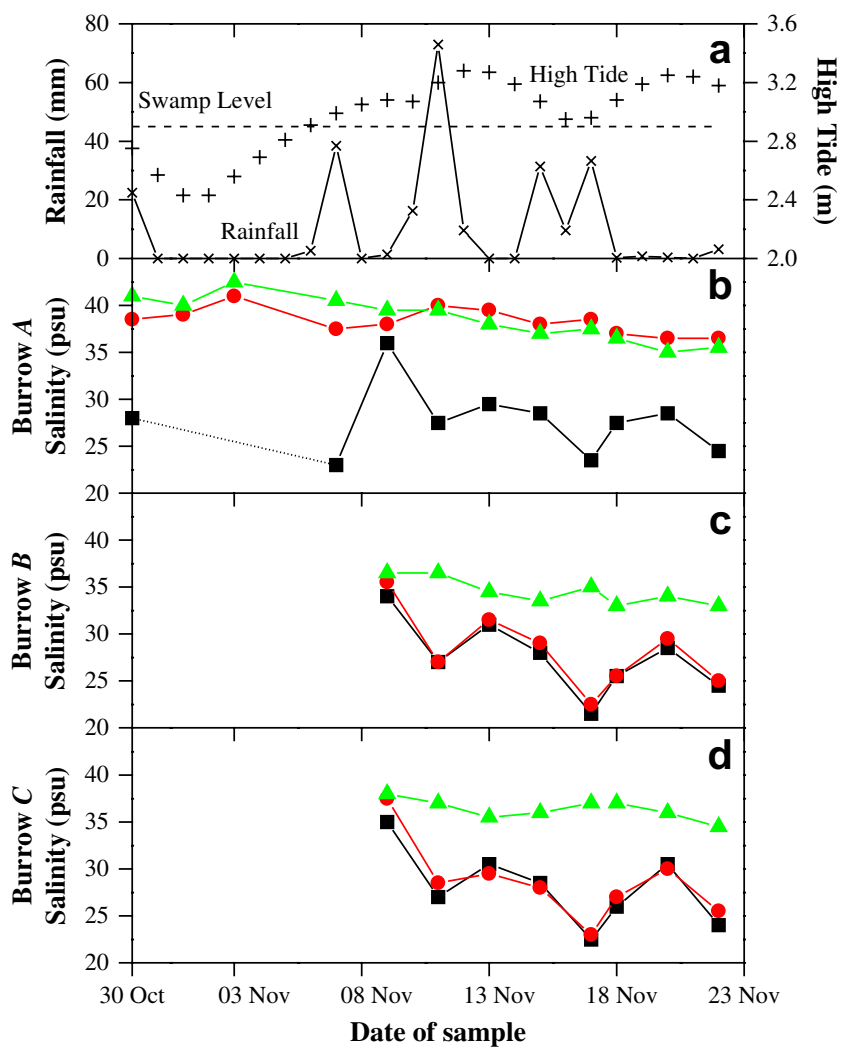

Fig. 6. Salinity time series for fieldwork. (a) Time series of rainfall $(x)$ and higher high tides $(+)$ during the study period. The swamp level is indicated by the dashed line and signifies inundating tides. (b) Time series of sample salinities for burrow A. (c) Time series of sample salinities for burrow B. (d) Time series of sample salinities for burrow C. (Top sample - black square, middle sample - red circle, lower sample - green triangle; dotted lines indicate no sample was available.)

loops, the volume of burrow water removed is increased, as compared with single-loop burrows. Thus, multiple-loop burrows show a clear advantage in tidal flushing. In addition, the flushing characteristics predicted by the model are consistent with previous observations in that there is a depth limit to which flushing occurs.

The model output suggests that two outcomes of tidal inundation (i.e., the flushing of burrows or an equilibrium state is reached) both occur rapidly. During tidal inundations, the surface-water slope is greatest at the beginning and end of the inundation. As such, the maximum flushing depth will be attained when tidal waters first impinge upon a burrow or last depart. If the modelled water slope reflects the initial

Table 3

Salinity of tidal water for three tidal events during 30 Oct-22 Nov 2000

\begin{tabular}{lll}
\hline Date (2000) & Source & $\begin{array}{l}\text { Salinity } \\
(\mathrm{psu})\end{array}$ \\
\hline 18 Nov & Ebb tide & 26.0 \\
& Stuart Creek & 27.5 \\
$20 \mathrm{Nov}$ & (during ebb) & \\
$22 \mathrm{Nov}$ & Ebb tide & 30.5 \\
\hline
\end{tabular}

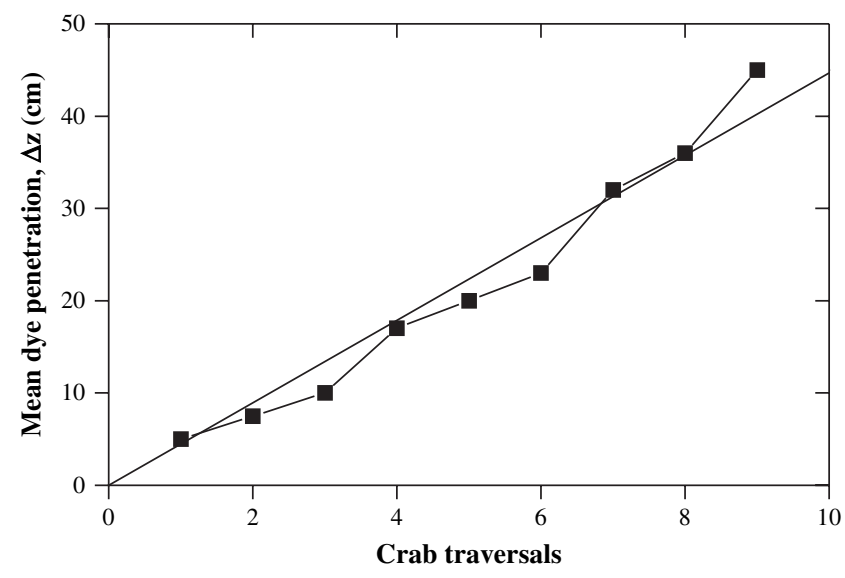

Fig. 7. Mean penetration, $\Delta z$, of dyed, saline water into fresh water with the number of burrow traversals by the crab. Burrow diameter was $3 \mathrm{~cm}$.

flood-tide slope then the model should provide an accurate indication of the fraction of the burrow that is flushed.

The field measurements (Fig. 6) show an obvious correlation between the middle and bottom salinities of burrow A, and between the top and middle samples from burrows $\mathrm{B}$ and $\mathrm{C}$. This suggests that the influence of swamp surface effects reaches to the middle depth of burrows $B$ and $C$ but not to the middle depth of burrow $\mathrm{A}$, for this study site and over the range of burrow salinities shown (20-35 psu). This implies that there is a depth beyond which flushing did not occur, consistent with the prediction of the numerical models. The trend in the salinities for the bottom samples, over the week of the inundations, was to slowly decrease by about 5 psu. This suggests that salt was transported from the lower burrow water into the upper (less saline) burrow water.

Fig. 6 also shows a correlation between the salinity at the top of each burrow (black squares) with the rainfall through the study period. Rain events coincide with decreases in the salinity of the top samples; little to no rain coincides with a salinity increase. This "no-rain" salinity increase is of significant magnitude (3-13 psu) and within the timeframe of one day, suggesting that it is not due to the very slow diffusion from the lower burrow water and the surrounding sediment. The salinity increase can be explained by the replacement of burrow water with inundating creek water during a tide; i.e., tidal flushing.

The salinity of the tidal water shown in Table 3 is consistent with those of the top samples of each burrow, and with the middle samples from burrows B and C, on each of the sampled days. As all burrow samples were taken following a tidal event, these observations are consistent with the hypothesis that the burrows were only partially flushed by the inundating tide, and to a maximum depth of approximately $30-35 \mathrm{~cm}$.

The influence of animal motion through the interface between surface water and burrow water enhances the distribution of salt within the burrow. This also affects the density variation of the burrow water, leading to favourable conditions for flushing during subsequent tidal inundations.

By considering the mass flux of salt across the interface, $J$, and using Fick's law of diffusion, 
$J=-D \frac{\partial C}{\partial z}$

a direct estimate of the enhancement to the diffusion coefficient, $D$, can be made using the experimental result. The mass flux of salt moving by diffusion across the interface is given by

$J=\frac{M}{A \Delta t}$

where $M$ is the mass of salt transported, $A$ is the tube crosssectional area, and $\Delta t$ is the time of the motion. Fig. 8 shows the schematic distribution of salt concentration due to diffusion through time, where the dashed line is the initial distribution. This shows that approximately one-quarter of the salt content in the volume of the mixed region (from $-z_{0}$ to $z_{0}$ ) is moved across the initial interface position; this fraction of the salt content is independent of the particular value of $\Delta z$. Thus, the mass of salt transported across the interface may be approximated to first-order by:

$M=C\left(\frac{1}{4} V\right)=C\left(\frac{1}{4} A \Delta z\right)$.

Thus, the mass flux across the interface is

$J=\frac{C \Delta z}{4 \Delta t}$

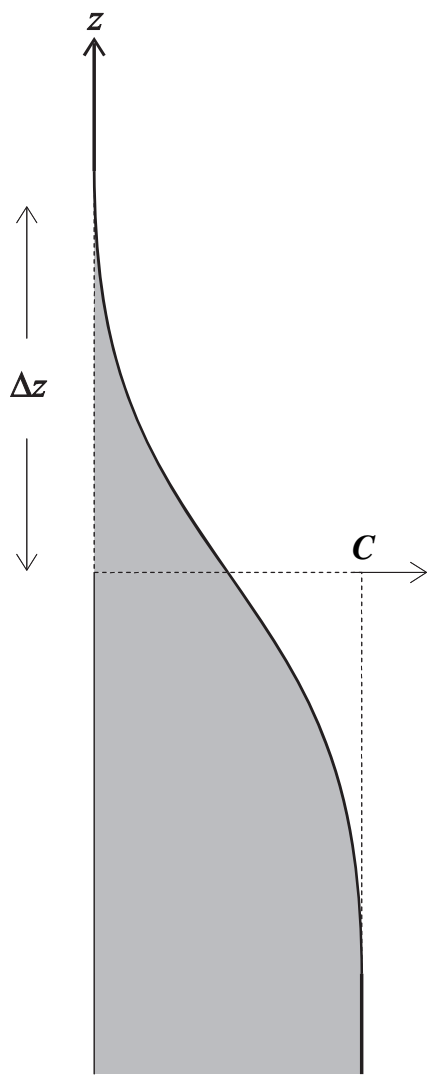

Fig. 8. Salt concentration distribution after a time of mixing. The dashed line shows the initial concentrations.
The concentration gradient of the mixing in the vertical direction may be approximated by

$\frac{\partial C}{\partial z}=\frac{(0-C)}{2 \Delta z}$,

and combining this with Eq. (4) gives an estimate for the diffusion coefficient of

$D=-J / \frac{\partial C}{\partial z}=\frac{(\Delta z)^{2}}{2 \Delta t}$.

Using the measured value of the penetration distance, $\Delta z=0.045 \mathrm{~m}$, and the average settling time of the eddies, $\Delta t=12.5 \mathrm{~s}$, the diffusion coefficient is calculated to be $8 \times 10^{-5} \mathrm{~m}^{2} \mathrm{~s}^{-1}$.

A theoretical estimate of the diffusion coefficient was determined by observing the turbulent eddies as the crab passed through the burrow. The length scale of the eddies, $L$, was taken as the diameter, $2-3 \mathrm{~cm}$, and settling of the turbulence defined the time scale, $T$, as $10-15 \mathrm{~s}$. Using the midpoints of these ranges provides us with an estimate of the eddy diffusion coefficient as

$D_{\mathrm{e}}=\frac{L^{2}}{T}=5 \times 10^{-5} \mathrm{~m}^{2} \mathrm{~s}^{-1}$.

The two calculated values for the diffusion coefficient are in surprisingly good agreement, considering the assumptions made in each calculation. The magnitude of the calculated diffusion coefficients is of the order of $10^{4}$ times that of the free diffusion of salt in water (Weast, 1981).

These values are valid for repeated traversals through the density interface with the minimum time interval between traversals, i.e., near continuous animal motion across the interface. If a rest interval between traversals is included, the time used in Eqs. (9) and (10) must account for this. Burrow structures within mangrove swamps have been observed to have approximately one resident animal per surface opening (Stieglitz, personal communication). Thus, each density interface in a given burrow is influenced by, on average, one crab. From observations of surface movement, a reasonable estimate of the number of traversals made by each crab is of the order of 10 per day. Assuming the density interface is traversed 10 times daily, the time between traversals (and also the settling time for the eddies) is approximately $2 \mathrm{~h}$. Using this value for time suggests a diffusion coefficient of the order of $10^{-7} \mathrm{~m}^{2} \mathrm{~s}^{-1}$, still $10^{2}$ times that of the free diffusion of salt in water. Each traversal of the animal across the interface causes a significant mixing of the different salinity waters. This effect may have a significant bearing on the flushing of burrows during each inundation, as well as over the several inundations of the tidal cycle.

\section{Conclusion}

Computational models and field observations support the hypothesis that complex burrow structures experience significant hydraulic flushing during tidal inundations and that there 
is a depth limit to which flushing occurs. Field data suggest this depth limit to be around 30-35 cm. Periscope loops can significantly enhance the volume of burrow water that is replaced, dependent upon their location. Motion of resident animals increases the rate at which salt (and therefore density) is redistributed within burrows, which can lead to an enhancement in flushing during subsequent tidal events.

\section{References}

Allanson, B.R., Skinner, D., Imberger, J., 1992. Flow in prawn burrows. Estuarine, Coastal and Shelf Science 35, 253-266.

Ball, M.C., 1988. Salinity tolerance in the mangroves Aegiceras corniculatum and Avicennia marina. I. Water use in relation to growth, carbon portioning and salt balance. Australian Journal of Plant Physiology 15, 447-464.

Fluid Dynamics International, 1993. Fluid Dynamics Analysis Package v7.0 Theory Manual. FDI, Evanston.

Harvey, J.W., Chambers, R.M., Hoelscher, J.R., 1995. Preferential flow and segregation of porewater solutes in wetland sediment. Estuaries 18, $568-578$.

Heron, S.F., Hollins, S.E., Ridd, P.V., 2002. The use of conductivity probes to locate animal burrows in mangrove swamps. IEEE/MTS Oceans 2002 Conference Proceedings, 28-31 Oct 2002, Biloxi, USA, pp. 1071-1077.

Heron, S.F., Ridd, P.V., 2001. The use of computational fluid dynamics in predicting the flushing of animal burrows. Estuarine, Coastal and Shelf Science 52, 411-421.

Heron, S.F., Ridd, P.V., 2003. The effect of water density variations on the tidal flushing of animal burrows. Estuarine, Coastal and Shelf Science 58, $137-145$.

Hollins, S., 2001. The Role of Crab Burrows in the Transport of Salt and Oxygen in Mangrove Soils. Ph.D. thesis, James Cook University, Australia, 126 pp.
Hollins, S., Ridd, P.V., Read, W.W., 1999. Measurement of the diffusion coefficient for salt in salt flat and mangrove soils. Mangroves and Salt Marshes 73, 1-6.

Lugo, A.E., Evink, G., Brinson, M.M., Broce, A., Snedaker, S.C., 1975. Diurnal rates of photosynthesis, respiration and transpiration in mangrove forests of South Florida. In: Golley, F.B., Medina, E. (Eds.), Tropical Ecological Systems: Trends in Terrestrial and Aquatic Research. Springer-Verlag, New York, pp. 335-350.

Nye, P.H., Tinker, B., 1977. Solute Movement in the Soil-Root System. Blackwell Scientific Publications, Oxford.

Passioura, J.B., Ball, M.C., Knight, J.H., 1992. Mangroves may salinize the soil and in so doing limit their transpiration. Functional Ecology 6 , 476-481.

Ridd, P.V., 1996. Flow through animal burrows in mangrove creeks. Estuarine, Coastal and Shelf Science 43, 617-625.

Scholander, P.F., Bradstreet, E.D., Hammel, H.T., Hemmingson, E.A., 1968. Sap concentrations in halophytes and some other plants. Plant Physiology 41, 529-532.

Semeniuk, V., 1983. Mangrove distribution in Northwestern Australia in relationship to regional and local freshwater seepage. Vegetatio 53, 11-31.

Soto, R., Jimenez, J.A., 1982. Analisis fisonomico estructural del manglar de Puerto Soley, La Cruz, Guanacaste, Costa Rica. Revista de Biologia Tropical 30, 161-168.

Stieglitz, T., Ridd, P., Muller, P., 2000. Passive irrigation and functional morphology of crustacean burrows in a tropical mangrove swamp. Hydrobiologia 421, 69-76.

Tomlinson, P.B., 1986. The Botany of Mangroves. Cambridge University Press, Cambridge, pp. 127-128.

Weast, R.C., 1981. CRC Handbook of Chemistry and Physics, 60th ed. CRC Press, Inc., Boca Raton. 3rd Printing.

Webster, I.T., 1992. Wave enhancement of solute exchange within empty burrows. Limnology and Oceanography 37, 630-643.

Wolanski, E., Ridd, P., 1986. Tidal mixing and trapping in mangrove swamps Estuarine, Coastal and Shelf Science 23, 759-771. 